\title{
STRATEGY OF MILLING CENTER THERMAL ERROR COMPENSATION USING A TRANSFER FUNCTION MODEL AND ITS VALIDATION OUTSIDE OF CALIBRATION RANGE
}

\author{
M. Mareš ${ }^{1 *}$, O. Horejš1, Š. Fiala ${ }^{1}$, Ch. Lee ${ }^{2}$, S. M. Jeong², K. H. Kim² \\ ${ }^{1}$ Czech Technical University in Prague, Research center of Manufacturing Technology, Prague, Czech Republic \\ ${ }^{2}$ Doosan Machine Tools, Seoungsan-gu, Changwon-si, Gyeongsangnam-do, Korea \\ *Corresponding author; e-mail:m.mares@rcmt.cvut.cz
}

\begin{abstract}
Achieving high workpiece accuracy is a long-term goal of machine tool designers. There are many causes of workpiece inaccuracy, with thermal errors being the most dominant. Indirect compensation (using predictive models) is a promising strategy to reduce thermal errors without increasing machine tool costs. A modelling approach using thermal transfer functions (a dynamic method with a physical basis) has the potential to deal with the issue. The method does not require any intervention into the machine tool structure and its modelling and calculation speed are suitable for real-time applications with results of up to $80 \%$ thermal error reduction. Compensation models for machine tool thermal errors based on transfer functions (TFs) were successfully applied on various kinds of single-purpose machines (milling, turning, floor-type, etc.) and implemented directly into various control systems. The aim of this research is to prove the compensation model applicability within the real machining conditions whereas the most of known thermal errors models end up with offline verification of their approximation quality. The introduced model of a milling centre operates in two machining directions $Y$ and $Z$ and describes thermal errors caused by spindle speed, feed drives and ambient temperature influences. The model is implemented into machine tool control system (Fanuc FS31i-B5). The real-time verification upon finishing cutting operation and conditions different from model calibration is discussed in more detail.
\end{abstract}

\section{Keywords:}

Thermal error; Compensation; Accuracy; Machine tool; Cutting process

\section{INTRODUCTION}

Challenges for machining include greater and greater material removal rates coupled with an increase in the use of difficult-to-machine materials, as well as environmentallyfriendly dry or MQL machining. These trends lead to a large (and variable) heat input into the machine structure causing thermo-elastic displacements of the machine tool (MT). Consequently, up to $75 \%$ of the overall geometrical errors of machined workpieces are caused by the temperature effects [Mayr 2012]. Software compensation of thermally induced displacements at the tool center point (TCP) is one of the widely employed techniques to reduce mentioned above errors due to its cost-effectiveness and ease of implementation.

Although real-time software compensations of thermal errors exist, the majority of these models is not sufficiently validated in real finishing operations using test piece. Some of these approaches only presume MT thermo-mechanical behaviour under similar conditions to calibration measurements [Xiang 2018], steady states [Achour 2019] or present simulations with little reference to practical applicability [Vyroubal 2012], [Thiem 2017], [Li 2018].

On the contrary, recent research concentrates on the design of new test pieces which are able to capture the thermal errors of machine tools. A previous design of a geometrical test piece for the measurement of thermally induced error motions of rotary axes is extended in [lbaraki, 2014]. In [Höfer 2017], the idea of a compact test piece for the evaluation of the thermally induced translational displacements of the TCP is presented. A thermal test piece for 5-axis machine tools for evaluating thermal errors of machine tools equipped with rotary tables is introduced in [Wiessner 2018]. However, the main purpose of research mentioned above is to quantitatively visualize thermally induced errors on thermal test piece by imprinting these errors. Thereafter, the thermal test piece can either be evaluated with a coordinate measuring machine (CMM) or manually with handheld measurement devices etc. The application of thermal test piece for evaluation of the realtime software compensations of thermal errors is missing. Although, in [Höfer 2017] is mentioned that the comparative evaluation of the investigated thermal errors compensation methods requires for all machines the same test workpiece and a comparable motion sequence to warm up the machine.

An approach to thermal error modelling of a milling centre including main thermal sources affecting MT structure in regard to direct industrial use is proposed in this research. Compensation model (a system of transfer functions - TFs) based on calibration according to international standards 
ISO 230-3 [ISO 2007] is implemented into MT control system (Fanuc FS31i-B5). The approach is verified out of its calibration range during the finishing cutting conditions and different MT axis configurations.

The workflow of introduced research began with probes mounting on MT structure. Diagnostic device set-up followed for maintaining the communication with MT control system and data acquisition. Calibration measurements could be realised subsequently. When all tests are completed measured data had to be processed. Therma error compensation model was composed afterwards based on experimental data. The mathematical model was implemented directly into MT control system at last and activated for final validation in real cutting conditions.

\section{.EXPERIMENT SET-UP AND CONDITIONS}

All of the experiments were performed on a 5 axis milling centre VC 630/5AX by Doosan (Fig. 1). The maximum spindle speed is $12000 \mathrm{rpm}$. The MT is equipped by efficient cooling system of the spindle and $Z$ axes motor.

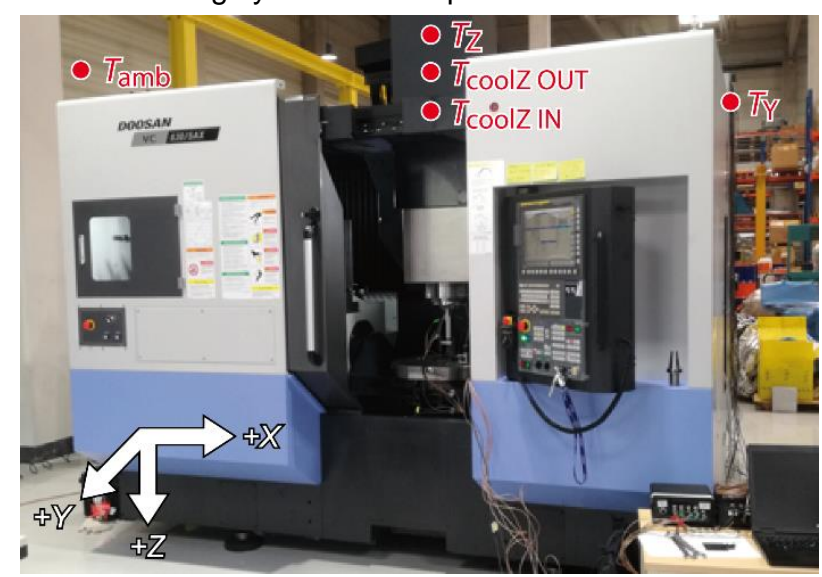

Fig. 1: Doosan VC 630/5AX milling center.

Five external sensors (Pt100, Class A, 3850 ppm/K) are used to record temperature behavior of $Y$ and $Z$ axis ball screw housing $\left(T_{Y}, T_{Z}\right), Z$ axes motor coolant inlet, outlet (expressed as temperature difference $\left.d T_{\text {coolZ }}=T_{\text {coolZ OUT }}-T_{\text {coolZ IN }}\right)$ and ambient temperature changes $\left(T_{\mathrm{amb}}\right)$. Approximate positions of external temperature sensors are depicted in Fig. 1. Another two temperature signals are used directly from MT control system: spindle front bearings ( $\left.T_{\mathrm{sp}}\right)$ and temperature of MT base ( $\left.T_{\text {base }}\right)$. Positions of temperature sensors used in MT control system are depicted in Fig. 2.
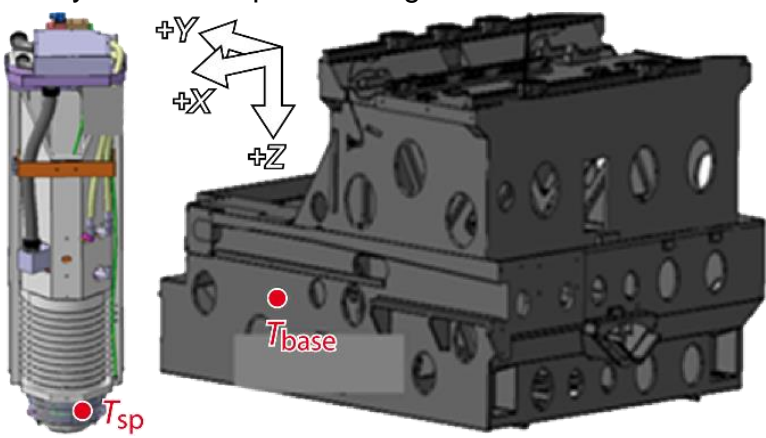

Fig. 2: Positions of temperature sensors used in MT control system.

Capacitive sensors (PR6423) firmly clasped in a measuring fixture are employed for noncontact sensing of displacements between a mandrel (length $125 \mathrm{~mm}$, diameter $40 \mathrm{~mm}$ ) and a table (regular position of a workpiece). Experiment set-up according to ISO 230-3 international standard [ISO 2007] is shown in Fig. 3.

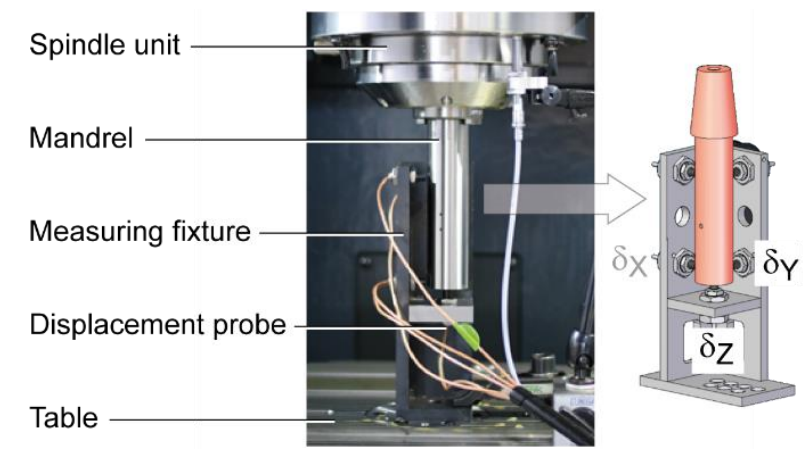

Fig. 3: Experiment set-up, measuring fixture.

Other information (spindle speed and feed drives) are taken directly from the MT control system.

All of the results and conclusions are associated with the following experiment conditions: load-free (without a cutting during a calibration process), calibration in one MT axis configuration (without any reference to volumetric errors).

The modelling effort is further focused on linear deformations in $Y$ and $Z$ directions. Thermal deformations in $X$ direction were also measured and considered as negligible due to the thermal symmetry of the MT structure. Taking into account of angular deformations is over the content of the research.

The further described compensation model based on TFs concentrates on thermally induced deflections caused by spindle rotation, feed rate in $Y$ and $Z$ axes and MT ambient temperatures.

\section{MODELLING AND IMPLEMENTATION}

All data processing and TF identification, as well as MT thermal behaviour modelling are performed in Matlab and Matlab Simulink (version R2017a).

The concept behind the modelling approach lies in usage of minimum additional gauges (only information from the MT control system if possible), an open structure, real time application and ease of implementation into the MT control system. A set of TFs appears to be a suitable tool.

The compensation strategy based on TFs is a dynamic method with a physical basis. A discrete TF is used to describe the link between the excitation and its response:

$y(t)=u(t) \cdot \varepsilon+e(t)$,

where $u(t)$ is the TF input vector in the time domain, $y(t)$ is the output vector in the time domain, $\varepsilon$ represents the TF in the time domain and $e(t)$ is the disturbance value. The differential form of the TF is introduced in eq. (2),

$$
\begin{aligned}
y(k)= & \frac{u(k-n) a_{n}+\cdots+u(k-1) a_{1}+u(k) a_{0}}{b_{0}}- \\
& -\frac{y(k-m) b_{m}+\cdots+y(k-1) b_{1}}{b_{0}}
\end{aligned}
$$

where $k-n(k-m)$ signifies the $n$-multiple (m-multiple) delay in sampling frequency. Linear parametric models of ARMAX (autoregressive moving average exogenous) identifying structure are used [Ljung 2009]. 
Excitations in the case of the employed TFs mean temperatures measured close to heat sinks or sources and the responses stand for the linear deflections in the examined directions. An approximation quality of the simulated behaviour is comparison of peak-to-peak values (differences of maximal and minimal simulated or measured deformations).

Approximation models based on TFs have advantage in use of a superposition principle (introduced also in [Brecher 2004]) of all participating elements mentioned at the end of chapter 2. Those model structures could be expressed as follow:

$\delta_{i}=\sum_{j=1}^{k}\left[\left(\Delta T_{j}-\Delta T_{a m b}\right) \cdot \varepsilon_{j}\right]+\Delta T_{a m b} \cdot \varepsilon_{k+1}$,

where (in this research) $i=Y, Z$ and $k$ is number of considered thermal sources (sinks) instead of MT surrounding. Temperature inputs $\left(T_{\mathrm{j}}, T_{\mathrm{amb}}\right)$ are used in relative coordinates $\left(\Delta T_{\mathrm{j}}, \Delta T_{\mathrm{amb}}\right)$.

Based on eq. (3) the approximation of thermal deformations in $Y$ direction between the spindle (tool position) and the table (workpiece fixturing) is possible to express by eq. (4),

$$
\begin{array}{r}
\delta_{Y T F}=\underbrace{\left(\Delta T_{\text {sp }}-\Delta T_{\text {base }}\right) \cdot \varepsilon_{1}}_{\text {spindle speed }}+\underbrace{\left(\Delta T_{Y}-\Delta T_{\text {base }}\right) \cdot \varepsilon_{2}}_{\text {feed rate } Y}+ \\
+\underbrace{\left(\Delta T_{Z}-\Delta T_{\text {base }}\right) \cdot \varepsilon_{3}}_{\text {feed rate } Z}+\underbrace{\Delta T_{\text {amb }} \cdot \varepsilon_{4}}_{\text {MT surround }}
\end{array}
$$

and in $Z$ direction by eq. (5),

$$
\begin{aligned}
\delta_{Z T F}= & \left(\Delta T_{s p}-\Delta T_{\text {base }}\right) \cdot \varepsilon_{5}+\left(\Delta T_{Y}-\Delta T_{\text {base }}\right) \cdot \varepsilon_{6}+ \\
& +d T_{Z c o o l} \cdot \varepsilon_{7}+\Delta T_{a m b} \cdot \varepsilon_{8},
\end{aligned}
$$

where $\delta \mathrm{YTF}$ and $\delta \mathrm{zTF}$ are simulated approximation values. $T_{\text {base }}$ is used to eliminate ambient temperature impact on measured temperatures of internal heat sources (spindle and feed drives). $T_{\mathrm{amb}}$ is used to cover deformational impact of MT surrounding itself due to the better correlation with measured deformations contrary to $T_{\text {base }}$.

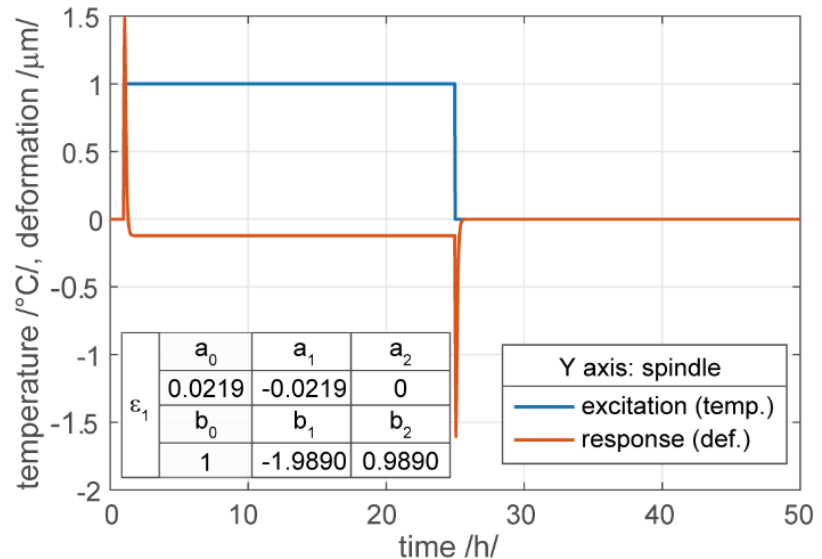

\subsection{Calibration and identification}

Generally, calibration should describe a transient characteristic between two thermodynamic equilibria; one with the MT surroundings and one with all active thermal sinks and sources meant to be approximated.

The setup of four calibration measurements (necessary to obtain information about the contribution of each heat source to the MT thermal error) is summarised in Tab. 1.

Tab. 1: Set-ups of calibration measurements.

\begin{tabular}{ccc}
\hline heat source & set-up & calibration time \\
\hline spindle & $12000 \mathrm{rpm}$ & $6 \mathrm{~h}$ (heating/cooling) \\
feed drive $\mathrm{Y}$ & $8000 \mathrm{~mm} \cdot \mathrm{min}^{-1}$ & $4 \mathrm{~h}$ (heating) \\
feed drive $\mathrm{Z}$ & $8000 \mathrm{~mm} \cdot \mathrm{min}^{-1}$ & $6 \mathrm{~h}$ (heating) \\
MT surrounding & & $48 \mathrm{~h}$ \\
\hline
\end{tabular}

Identification of thermo-mechanical system consists of two parts: measured data processing and estimation of TF calibration coefficients. The former includes selection of proper input / output signals, following signal filtering from undesirable frequencies caused by another sources than thermal behaviour, input signal expressing in relative coordinates etc. 40 hours was spent by measured data processing during the research. Estimation of TF calibration coefficients is executed with the help of Matlab identification toolbox. The iteration process takes several seconds.

The sets of identified TFs (out of the four calibration experiments summarised in Tab. 1) used in approximation model for $Y$ direction ( $\varepsilon_{1}$ to $\varepsilon_{4}$ in eq.(4)) and $Z$ direction $\left(\varepsilon_{5}\right.$ to $\varepsilon_{8}$ in eq.(5)) are examined through a linear time invariant (LTI) step response. The LTI expresses clear dependency between excitation (temperature) and response (deformation) of the thermo-mechanical system. Moreover, the stability of each TF can be proved. LTI diagrams for transfers used in eq.(4) are shown in Fig. 4 and Fig. 5. LTI diagrams for transfers used in eq.(5) are shown in Fig. 6 and Fig. 7. The calibration coefficients of identified TFs for approximation of MT thermal errors are presented in the figures as well.

Fig. 4: Step responses and coefficients of identified thermo-mechanical systems for $Y$ direction thermal errors caused by: spindle rotation (left) and feed drive $Y$ (right). 

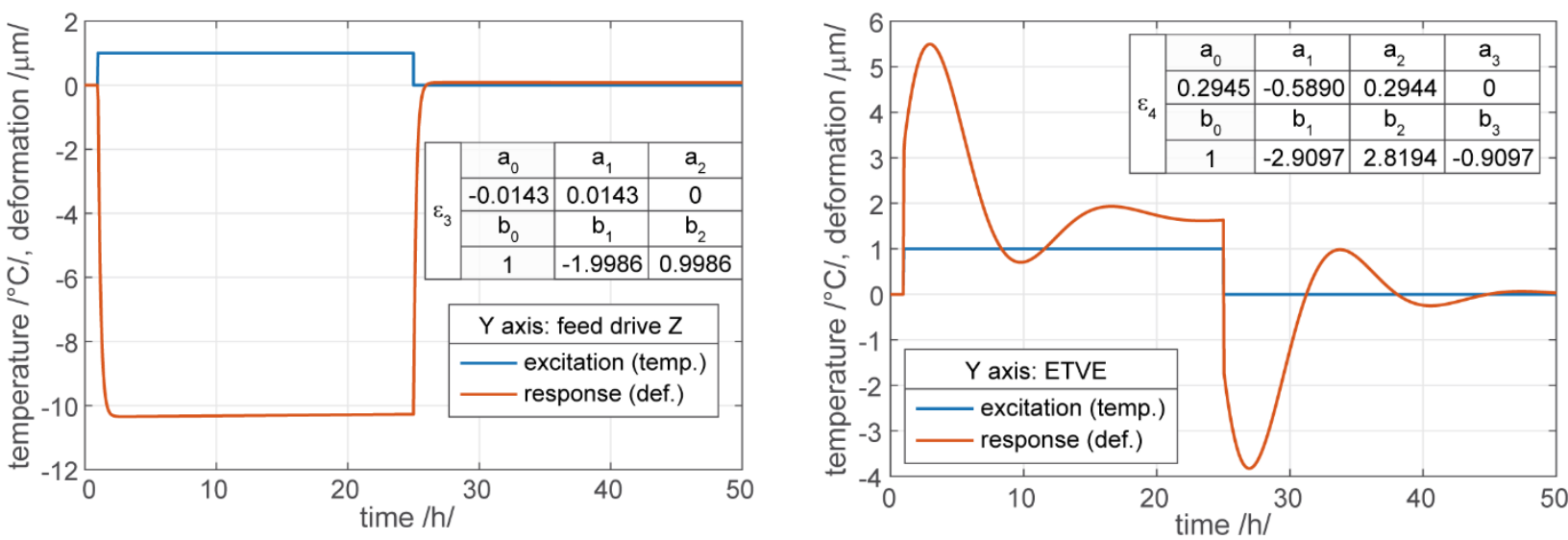

Fig. 5: Step responses and coefficients of identified thermo-mechanical systems for $Y$ direction thermal errors caused by: feed drive $Z$ (left) and MT surrounding (right).
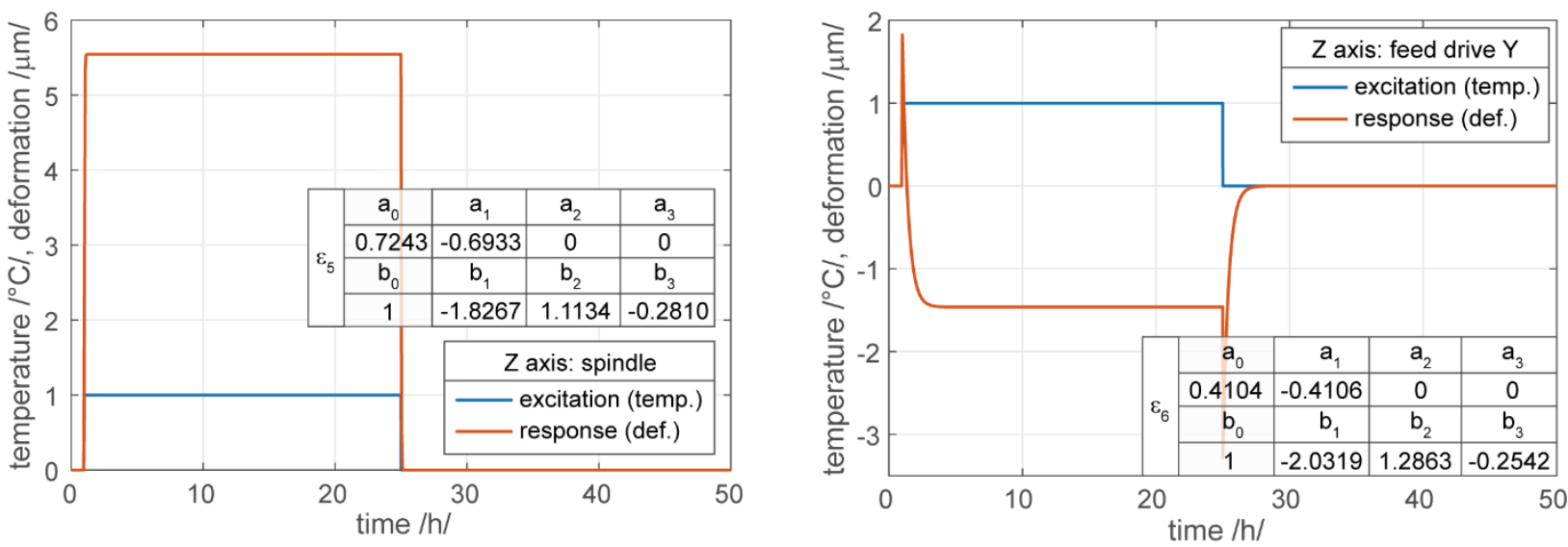

Fig. 6: Step responses and coefficients of identified thermo-mechanical systems for $Z$ direction thermal errors caused by: spindle rotation (left) and feed drive $Y$ (right).
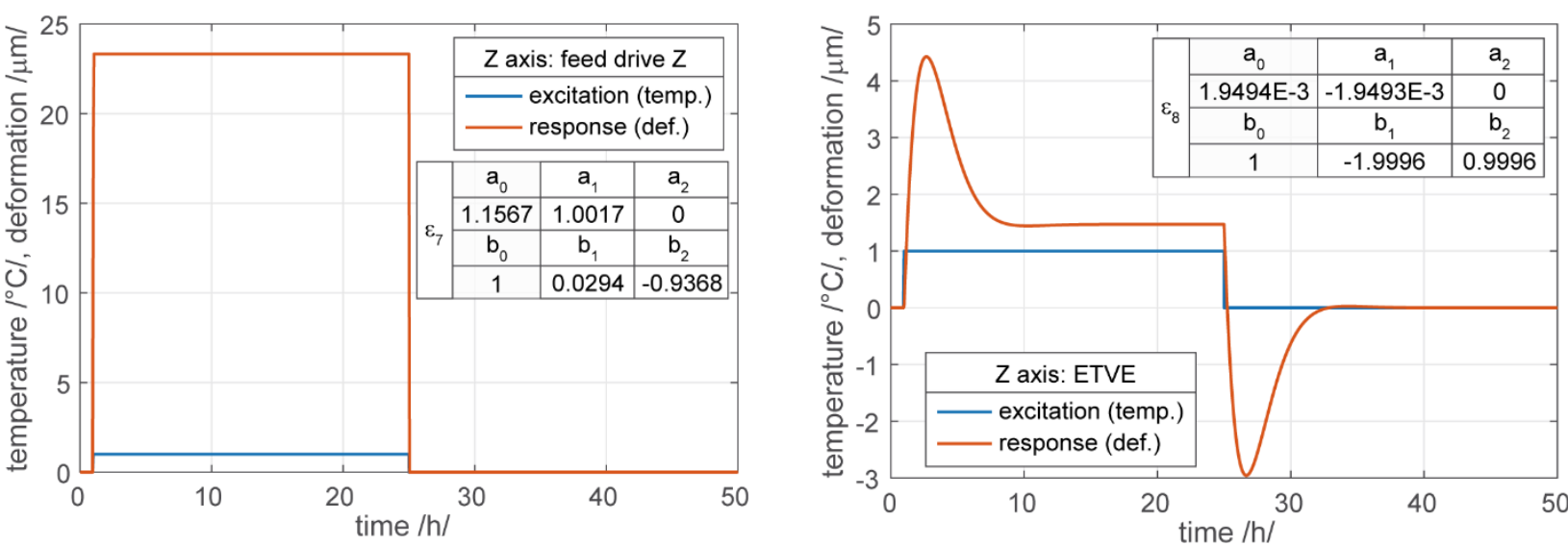

Fig. 7: Step responses and coefficients of identified thermo-mechanical systems for $Z$ direction thermal errors caused by: feed drive $Z$ (left) and MT surrounding (right).

A small impact of spindle and $Y$ axis activity on thermomechanical behaviour in $Y$ direction is observed both graphs in Fig. 4. An auto-compensation thermal errors effect during $Y$ and $Z$ feed drive mutual activity in $Z$ direction is expected (see opposing behaviours of responses in right graph in Fig. 6 and left graph in Fig. 7).

2.2 Model implementation into the MT control system The programmable automation controller (PAC) $\mathrm{N}$ CompactRIO (cRIO-9024) produced by National Instruments was used for data acquisition (sampling rate is 1 seconds) during calibration experiments (see Section 2). To speed up implementation process of thermal errors compensation model into FANUC CNC system (FS31i-B5), the same device was employed for thermal errors compensation. Therefore, a development of the communication between the data acquisition device (cRIO9024) and the FANUC CNC system was carried out. To enable bidirectional communication, the Focas library from FANUC was imported into LabVIEW software (LabVIEW 2013 SP1) which is standardly used for programming of $\mathrm{NI}$ CompactRIO controllers. Thus, developed LabVIEW software allows data acquisition of standard NC data (e.g. motors temperatures, coordinates, speeds, feed rates etc.) and also sending back calculated thermal error compensation values into Fanuc CNC control system in real-time. 


\section{APPLICATION AND VERIFICATION}

Two experiments have been designed to verify the validity of the compensation models. The firs verification test consists of all calibrated heat source mutual activities in regard to calibration conditions (measurement set-up according to ISO 230-3, see Fig. 3). The second verification test includes real machining (finishing conditions) in wider area of the MT workspace.

\subsection{Air cutting conditions}

Fig. 8 shows spindle speed, feed drive $Y$ and $Z$ configuration of the first verification test.

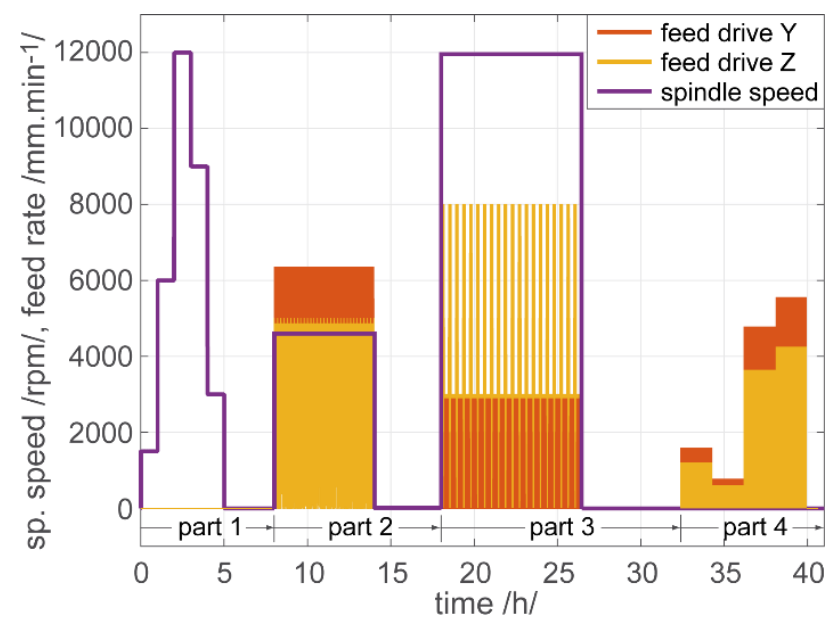

Fig. 8: Set-up for verification experiment.

The test is divided into 4 parts as highlighted in Fig. 8:

- Part 1 - spindle speed variation followed by a cooling phase.

- Part 2 - constant spindle speed and simultaneous movements in $Y$ and $Z$ axes followed by cooling phase.

- Part 3-spindle speed and movement in the axes (tool path) similar to the second test with the cutting (without machining and related to one MT axes configuration). The cooling phase of MT follows.

- Part 4 - variation of simultaneous feed drives $Y$ and $Z$ activities.

Thermo-mechanical system temperature inputs during the first verification test are depicted in Fig. 9.

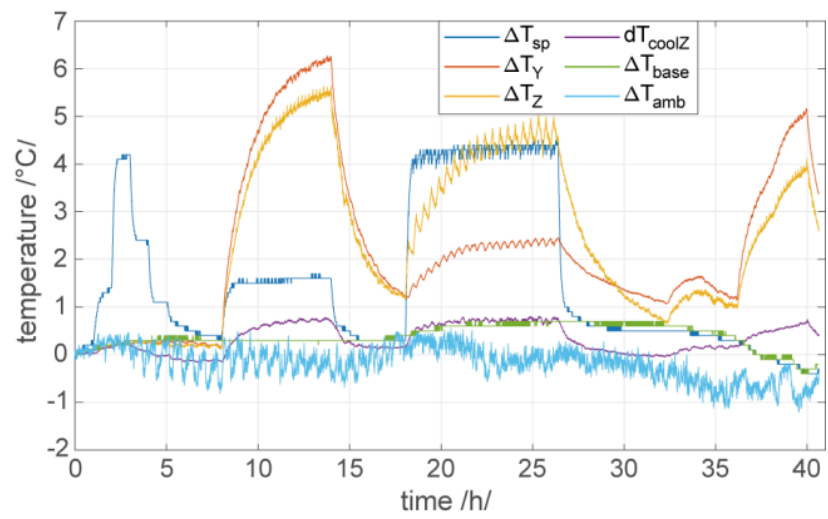

Fig. 9: Compensation model temperature inputs during the first verification test.

The TF models introduced in eq.(4) and eq.(5) were active in the MT control system during the test and deformations after compensation were measured (see Fig. 10).

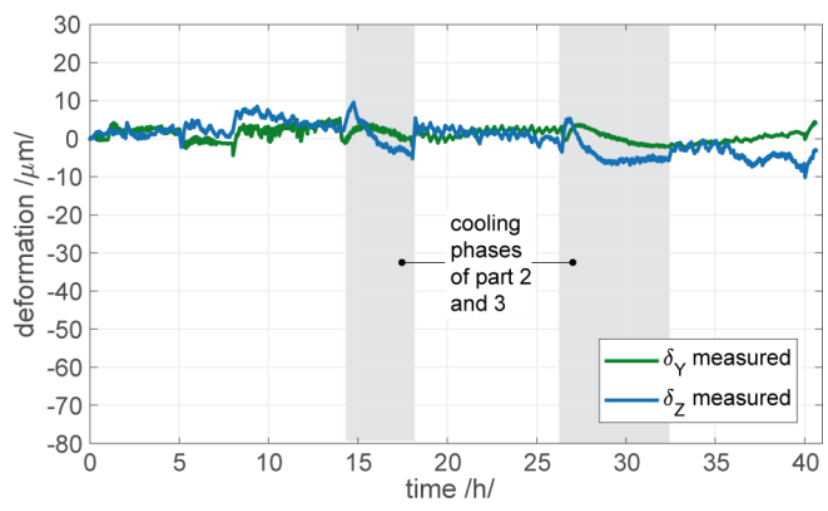

Fig. 10: Measured deformations (with compensation) during the first verification test.

An uncompensated state of the machine is offline calculated from known model outcomes ( $\delta \mathrm{YTF}$ and $\delta \mathrm{ZTF}$ given by eq.(4) and eq.(5)) and measured deformations after compensation. The result is shown in Fig. 11.

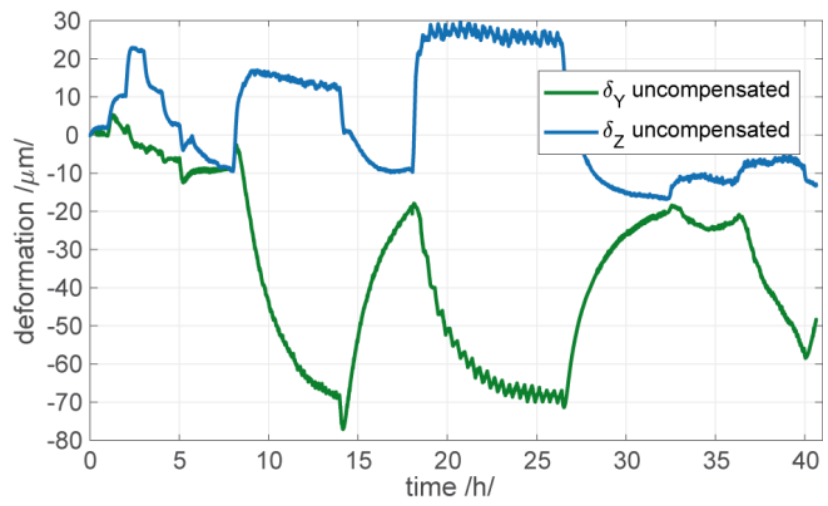

Fig. 11: Simulated MT thermo-deformational state without compensation during the first verification test.

The improvement of the thermo-mechanical state is 7.5 -fold (from 83 to $11 \mu \mathrm{m}$ ) in the $Y$ direction and 2.5-fold (from 47 to $19 \mu \mathrm{m})$ in the $Z$ direction compared to the uncompensated state. The highest prediction error is observed during cooling phases (end of the test part 2 and part 3 especially) in $Z$ direction (see Fig. 10). This could be caused by absence of forced convection (generated by spindle rotation) in cooling phase behaviour. Dividing model into separate description of both phases independently is recommended. The $Z$ direction auto-compensation effect of deformational elements belonging to axis movements is confirmed (see the last part in Fig. 11 where uncompensated deformations in $Z$ direction are very small).

\subsection{Finishing cutting conditions}

The second verification test is further introduced due to authentication of a practical applicability of the compensation models: during a real finishing machining and out of the model's calibration point.

Cutting parameters of the second verification test are presented in Tab. 2.

Tab. 2: Cutting conditions.

\begin{tabular}{cccc}
\hline $\begin{array}{c}\text { spindle speed } \\
/ \mathrm{rpm} /\end{array}$ & $\begin{array}{c}\text { feed rate } \\
/ \mathrm{mm} \cdot \mathrm{min}^{-1} /\end{array}$ & $\begin{array}{c}\text { pitch } \\
/ \mathrm{mm} /\end{array}$ & $\begin{array}{c}\text { depth of cut } \\
/ \mathrm{mm} /\end{array}$ \\
\hline 12000 & 3000 & 0.05 & 0.1 \\
\hline
\end{tabular}


A schema of a test workpiece profile along with description of the test realisation (a tool paths and adjusted feed rates of $Y$ and $Z$ axes) is presented in Fig. 12. Changing cutting conditions, such as the depth of cut, results in varying the cutting forces and leads to geometrical errors on machined workpieces. Thus before starting with the evaluation of thermal errors, the test workpiece is semifinished in a way that the milling forces during finishing are minimized in order to avoid influences of the cutting process distorting the thermal results (see profile of the test workpiece in Fig. 12).

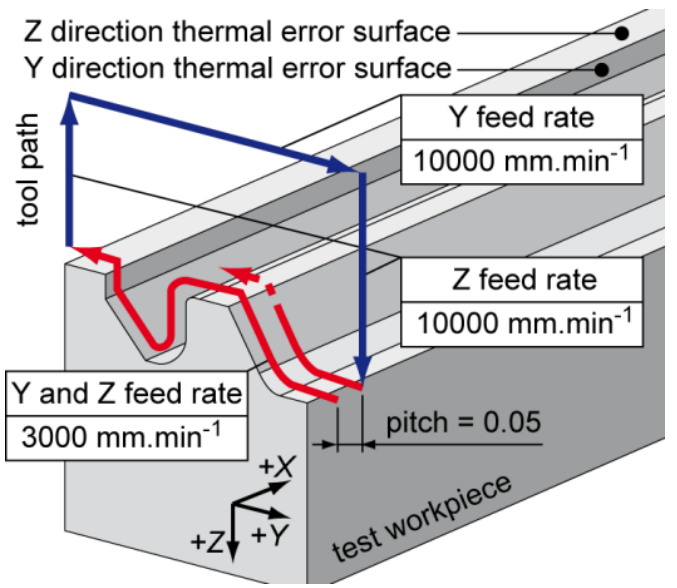

Fig. 12: Test workpiece machining process.

The test workpiece size is $400 \times 120 \times 110 \mathrm{~mm}$ and aluminium AL6061 of used material. The reasons for choosing aluminium as test workpiece material is that the material is quite cheap, available in manufacturing enterprises and the cutting forces are low compared to steel.

A ball nose cutter ( $\varnothing 6$ BALL AEB 2060S, TaeguTec company) was used. The cutting conditions alongside with the test workpiece length define total machining time to $15 \mathrm{~h}$ $30 \mathrm{~min}$. Surfaces decided to $Y$ and $Z$ thermal errors measurement are also pointed out in the Fig. 12.

A vice was used to the test workpiece clamping to the table as shown in Fig. 13. This fixturing has not high demands on parallelism accuracy of bearing and machining workpiece surfaces. Contrary, the test workpiece clamped by the described manner is not appropriate for inspection on coordinate measurement machine $(\mathrm{CMM})$.

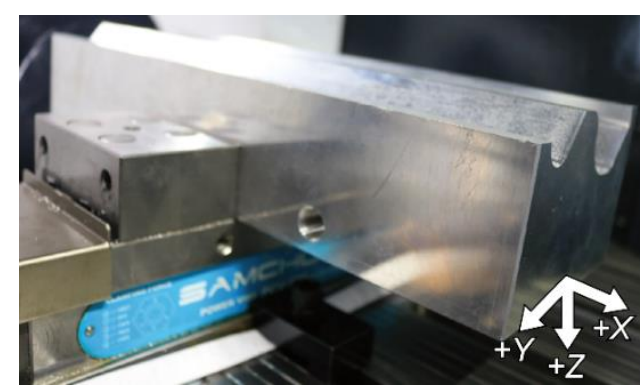

Fig. 13: Test workpiece fixed on the table.

The principle of deformation measurement in $Y$ and $Z$ direction is shown in Fig. 14. The test workpiece remained clamped on the table via the vice. The machined surfaces were carefully cleaned before the measurement. Measurement was carried out in cooled down state of the machine and test workpiece. Measuring device (a contact inductive displacement probe T071F, Peter Hirt $\mathrm{GmbH}$ ) was mounted on the spindle (with the help of a magnetic holder). The $X$ feed rate during the surface measurements was set up to $100 \mathrm{~mm} \cdot \mathrm{min}^{-1}$ and sampling frequency of the record to $100 \mathrm{~s}^{-1}$ for continuous data acquisition.
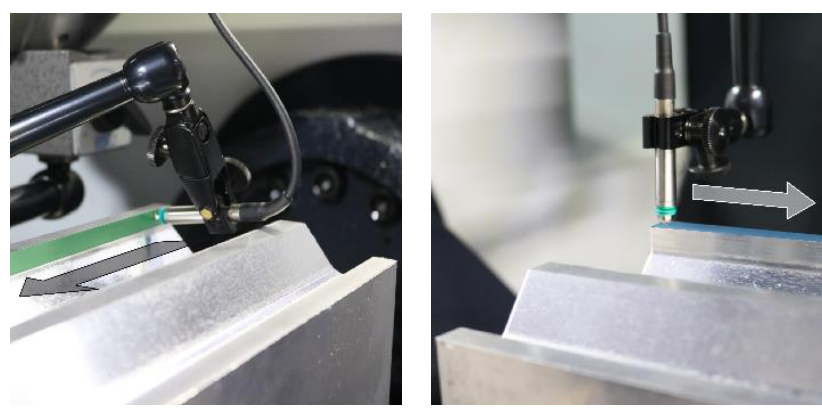

Fig. 14: $Y$ (left) and $Z$ (right) thermal errors measurement on test workpiece.

Fig. 15 shows real record of spindle speed, feed drive $Y$ and $Z$ during the second verification test.

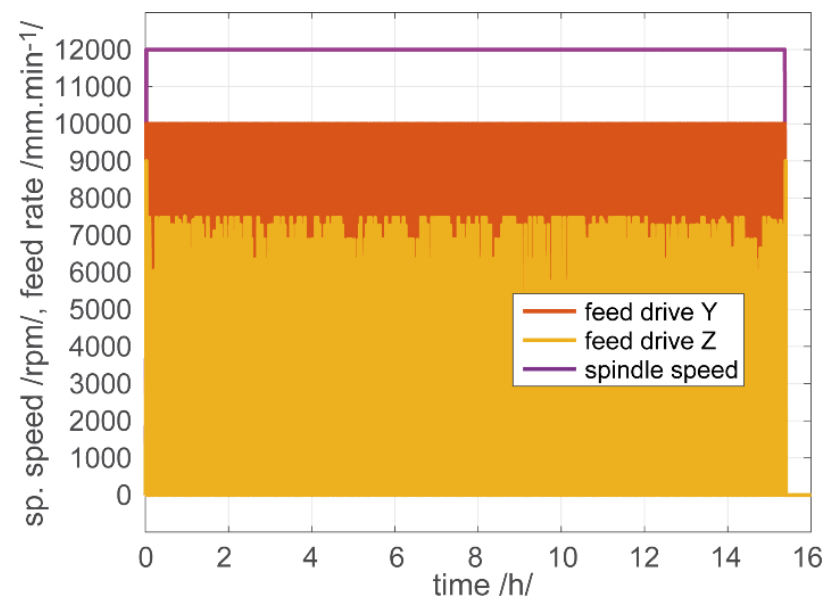

Fig. 15: Set-up for verification experiment within the finishing cutting conditions.

Thermo-mechanical system temperature inputs during the second verification test are depicted in Fig. 16.

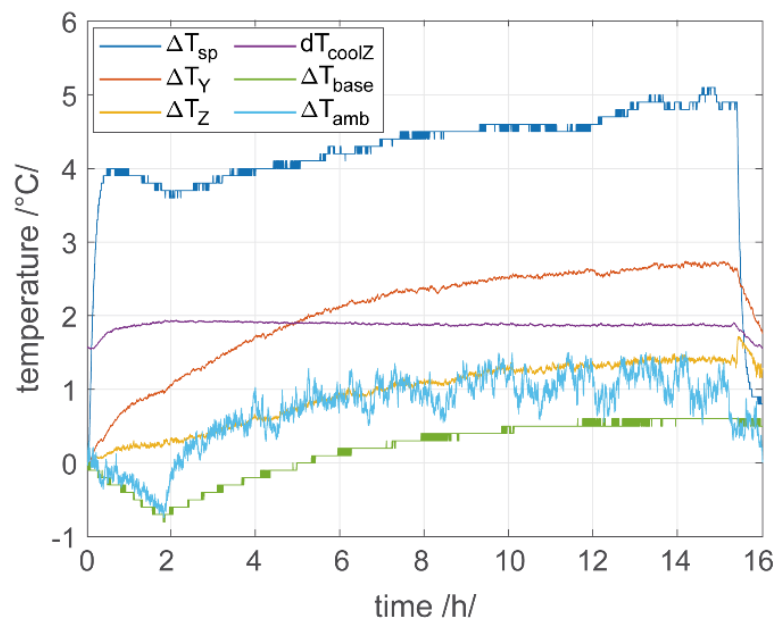

Fig. 16: Compensation model temperature inputs during the verification test during the finishing cutting conditions.

The $Y$ and $Z$ direction thermal error surfaces (see Fig. 12) were measured in three different positions with four repetition to evaluate uncertainty of Type A. From the twelve measurements the arithmetical mean was calculated. The arithmetical means of measured deformations in $Y$ and $Z$ directions after compensation with the highlighted areas of uncertainty are depicted in Fig. 17 


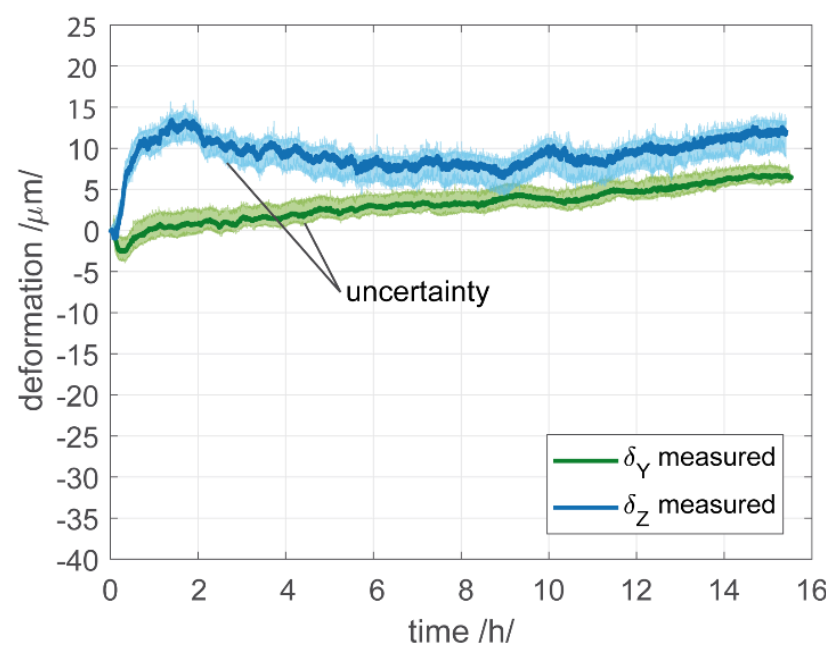

Fig. 17: Measured deformations (with compensation) during the finishing cutting test.

The uncompensated state of the MT (Fig. 18) is offline calculated from known model outcomes and arithmetical means of measured deformations after compensation.

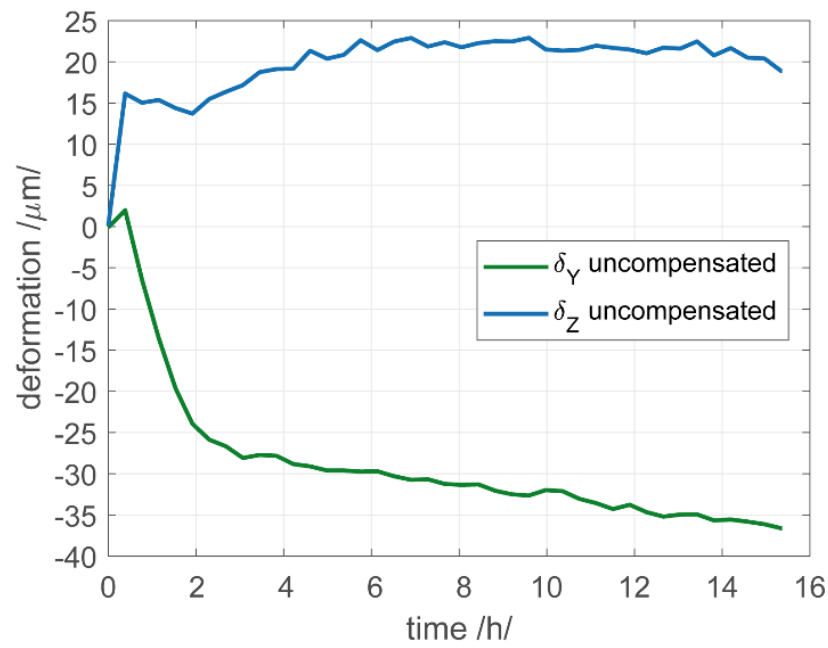

Fig. 18: Simulated MT thermo-deformational state without compensation during the finishing cutting test.

The improvement of the thermo-mechanical state is estimated 4.5-fold (from 38 to $8 \mu \mathrm{m}$ ) in the $Y$ direction and 1.8-fold (from 24 to $13 \mu \mathrm{m}$ ) in the $Z$ direction compared to the uncompensated state. An overreaction of the compensation model in $Z$ direction during finishing cutting process is discussed further.

\section{DISCUSION}

Since the part 3 of the first verification test contents of similar set-up to real machining both measured deformations with and without cutting process could be compared within the same chart (see Fig. 19).

The outcome of the thermal errors compensation model is satisfactory in $Y$ direction (left part of Fig. 19). Otherwise, the outcome of compensation model in $Z$ direction overreacted (right part of Fig. 19). The difference between measured deformations of both experiments defines finishing cutting process impact on $Z$ direction thermal errors as highlighted in the figure. The impact of cutting process (even finishing conditions) should be considered in MT thermal errors description.
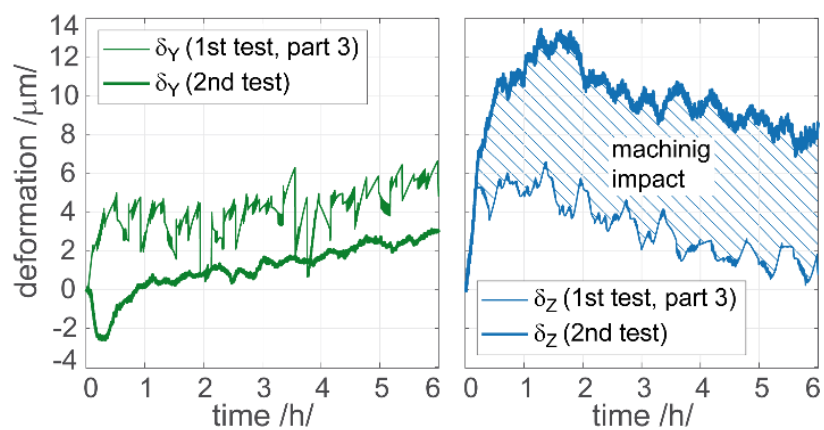

Fig. 19: Cutting process impact evaluation in $Y$ (left) and $Z$ direction (right) thermal error.

\section{SUMMARY}

The main objective of the scientific investigation presented in this paper is enhancement of MT accuracy by minimising thermal errors and verification of the compensation model validity out of its calibration area. The role of main thermal sinks and sources, elimination of their influence during the mutual activity, real-time application, long-term stability and minimal increase of the MT costs all represent basic requirements placed on compensation methods and TFs seem to be a suitable apparatus.

The tested machine was a milling center VC $630 / 5 \mathrm{AX}$ by Doosan. Calibration experiments were carried out under specific conditions: no cutting process was involved and the calibration was performed in one MT axes configuration according to ISO 230-3 [ISO 2007]. The developed compensation model approximates undesirable thermal errors caused by the spindle rotation, MT $Y$ and $Z$ axes movement and ambient temperature. Compensation was taken into account for linear deformation components in $Y$ and $Z$ directions. The thermal errors compensation model was implemented into the MT control system. The approximation quality of the model based on TFs was examined over two sets of experimental data: verification measurement consisting of all relevant thermal source mutual activities with similar conditions to calibration measurement and verification test consisting of real finishing cutting conditions. The results proved the model ability to wider industrial use. Dominant thermal sources participating on $Y$ and $Z$ errors and auto-compensation effects were defined within the MT type.

Practical conclusions in regard to MT thermo-mechanical behaviour are possible to summarise: the MT equipped with very effective cooling system (spindle and $Z$ feed drive) with positive impact on calibration time and overall thermal errors magnitude; significant differences between heating and cooling phases were observed.

The follow-up research will focus on considering of heating and cooling phase differences, rotary table thermal behaviour, compensation model transferability (nonlinear dependences of system inputs and outputs) between different machines of the same type and improvement of the test workpiece clamping due to a possibility of verification measurement realization on CMM.

\section{ACKNOWLEDGMENTS}

This paper was supported by the project cooperated with Doosan Machine Tools.

Doosan Machine Tools gratefully thank RCMT, which has helped us to apply the machine. 


\section{REFERENCES}

[Achour 2019] Achour, S., Checchi, A., Bissacco, G., De Chiffre, L. Thermal characterization of a micro polishing machine and effect on path strategy compensation. Proceedings of the euspen's 19th International Conference \& Exhibition, Bilbao, Spain, June, 2019, pp 446-447. ISBN 978-0-9957751-4-5

[Brecher 2004] Brecher C and Hirsch P, Compensation of thermo-elastic machine tool deformation based on control internal data. CIRP Annals - Manufacturing Technology, 2004, Vol. 53, No. 1, pp. 299-304.

[Chen 1996] Chen, J. S. A study of thermally induced machine tool errors in real cutting conditions, Int.J.Mach.Tools Manuf., 1996, Vol. 36, No. 12, pp. 14011411

[Höfer 2017] Höfer, H., Wiemer, H. Generation of motion sequences for thermal load of machine tools. Prod. Eng. Res. Devel., 2017, Vol. 11, pp. 75-83

[Horejš 2018] Horejš, O., Mareš, M. \& Hornych, J. Thermally induced displacements of machine tool structure, tool and workpiece due to cutting processes, 2018. Dresden, s.n., pp. 269-278

[lbaraki, 2014] Ibaraki, S., Ota, Y. A machining test to calibrate rotary axis error motions of five-axis machine tools and its application to thermal deformation test. International Journal of Machine Tools and Manufacture, Vol. 86, pp. 8188

[ISO 2007] ISO 230-3, Test Code for Machine Tools - Part 3: Determination of Thermal Effects, Genf, Switzerland, 2007, p. 44.

[Li 2018] Li, Y., Zhang, J., Su, D., Zhou, Ch., Zhao, W. Experiment-based thermal behavior research about the feed drive system with linear scale. Advances in Mechanical Engineering, 2018, Vol. 10, No. 11, p. 1-10

[Ljung 2009] Ljung L, System identification toolbox 7, User's guide, 2009

[Mareš 2017] Mareš, M., Horejš, O., Hornych, J. Modelling of Cutting Process Impact on Machine Tool Thermal Behaviour Based on Experimental Data. Procedia CIRP, 2017, Vol. 58, pp, 152-157

[Mayr 2012] Mayr J., et al., Thermal issues in machine tools. CIRP Annals - Manufacturing Technology, 2012, Vol. 61, No. 2, pp. 771-791

[Thiem 2017] Thiem, X., Kauschinger, B. Ihlenfeldt, S. Structure Model Based Correction of Thermally Induced Motion Errors of Machine Tools. Procedia Manufacturing, 2017, Vol. 14, pp. 128-13

[Vyroubal 2012] Vyroubal, J. Compensation of machine tool thermal deformation in spindle axis direction based on decomposition method. Precision Engineering, , 2012, Vol. 36 , pp. $121-127$

[Wiessner 2018] Wiessner, M., Blaser, P., Böhl, S., Mayr, J.; Knapp, W., Wegener, K. Thermal test piece for 5-axis machine tools. Precision Engineering, 2018, Vol. 52, pp. 407-417

[Xiang 2018] Xiang, S., et al. Dynamic linearization modeling approach for spindle thermal errors of machine tools. Mechatronics, 2018, Vol. 53, pp. 215-228, ISSN: 0957-4158 